\title{
A CONSTITUCIONALIZAÇÃO DO DIREITO PRIVADO: UM ESTUDO SOBRE SUA PERSPECTIVA HISTÓRICA E SOBRE A APLICAÇÃO DOS DIREITOS FUNDAMENTAIS NAS RELAÇÕES PRIVADAS
}

\author{
Vinicius Cassio Swarowski ${ }^{1}$ \\ Arthur Felipe Gressler ${ }^{2}$ \\ Ricardo Kipper ${ }^{3}$ \\ Aneline dos Santos Ziemann ${ }^{4}$ \\ Jorge Renato dos Reis ${ }^{5}$
}

\begin{abstract}
RESUMO
A pesquisa aqui documentada teve como foco principal a análise dos direitos fundamentais e a sua aplicação nas relações privadas. Com este intuito, a pesquisa realizada partiu de uma perspectiva histórica do direito civil, verificando desde suas bases individualistas até o seu viés mais humanizado, na contemporaneidade. A metodologia utilizada foi a pesquisa bibliográfica, ou seja, a leitura de livros, artigos e revistas científicas na área. A pesquisa finalizou com a análise da constitucionalização do direito privado. Este processo de constitucionalização teve início, no Brasil, com a promulgação da Constituição Federal de 1988. Foi realizada, também, uma rápida conceituação dos direitos fundamentais, bem como foram analisadas as "dimensões" destes direitos. Verificou-se que, contemporaneamente, todo o ordenamento jurídico brasileiro submete-se aos ditames constitucionais, de forma que as normas de direito privado não são exceção a esta regra.
\end{abstract}

Palavras-chave: Constitucionalização. Direito Privado. Direitos Fundamentais.

\begin{abstract}
The research documented here focused primarily on the analysis of fundamental rights and their application in private relations. To this end, the survey began with a historical perspective of civil law, from checking their individualistic bases until its more humane bias, nowadays. The methodology used was the literature research, ie reading books, articles and journals in the area. The research concluded with the analysis of the constitutionalization of private law. This process of constitutionalization began in Brazil, with the promulgation of the Constitution of 1988 was also made a quick conceptualization of fundamental rights, as well as analyzed the "dimensions" of these rights. It was found that nowadays, all the Brazilian legal system is subordinated to the constitutional dictates, so that the rules of private law are no exception to this rule.
\end{abstract}

Keywords: Constitutionalisation. Private Law. Fundamental Rights.

\footnotetext{
${ }^{1}$ Graduando em Direito pela Universidade de Santa Cruz do Sul - UNISC. <vcswarowski@gmail.com>

${ }^{2}$ Graduando em Direito pela Universidade de Santa Cruz do Sul - UNISC. <

${ }^{3}$ Graduando em Direito da Universidade de Santa Cruz do Sul - UNISC. <ricardo_kipper@hotmail.com>

${ }^{4}$ Mestranda em Direito da Universidade de Santa Cruz do Sul - UNISC. 〈aneziemann@ yahoo.com.br>

${ }^{5}$ Professor do Departamento de Direito da Universidade de Santa Cruz do Sul - UNISC. <jreis@unisc.br>
} 


\section{INTRODUÇÃO}

O direito civil passa, contemporaneamente, por profundas mudanças. Este ramo do direito, que outrora possuiu um viés estritamente individualista e patrimonialista, hoje se vê invadido por olhares mais solidários, voltados à promoção da dignidade humana e à atenção à função social dos seus institutos.

Os novos ares trazidos ao direito pela Constituição Federal de 1988 promoveram uma renovação substancial na forma de interpretação dos institutos do direito civil. A atenuação das fronteiras entre o que se denomina "Direito público" e "Direito privado" é uma das implicações da constitucionalização do direito. Com a intenção de verificar como se deu esta renovação, foi analisado o processo de constitucionalização do direito privado, sendo realizada pesquisa relativa aos direitos fundamentais e à possibilidade de vinculação destes direitos às relações jurídicas travadas entre particulares.

Assim, é apresentada uma retrospectiva histórica que se inicia nas origens do Direito Civil e chega até o seu processo atual de constitucionalização, seguida de conceituação dos direitos fundamentais, passando ao estudo da sua evolução e finalizando com a análise das suas "dimensões". Por fim, pretende-se demonstrar a inter-relação existente entre os tópicos anteriores mencionados, concluindo a pesquisa aqui exposta com a verificação em torno de algumas das teorias que permeiam as formas de incidência dos direitos fundamentais nas relações entre particulares.

\section{A CONSTITUCIONALIZAÇÃO DO DIREITO: BREVE ANÁLISE DOS ASPECTOS históricos do DIREITO CIVIL ATÉ O SEU PROCESSO DE CONSTITUCIONALIZAÇÃO}

Inicialmente, parece adequado buscar compreender os desdobramentos históricos do processo de constitucionalização do Direito. Assim, convém analisar a clássica separação do direito em dois ramos distintos: o Direito público, de um lado, e o Direito privado, de outro.

Os conceitos relativos a público e a privado são variáveis, mudando de acordo com diferentes épocas e lugares, e possuindo um liame cultural. Com o surgimento do Estado Liberal, houve a emergência de uma divisão entre as esferas pública e privada de forma mais intensa (SARMENTO, 2010). 
Sarmento (2010), ao explicar a situação em que a sociedade se encontrava neste período, menciona que "o Estado deveria cuidar da segurança interna e externa, protegendo a propriedade privada, mas não lhe cabia intervir nas relações travadas no âmbito da sociedade." (p. 41). O autor explica, também, no que tange as relações travadas no ambiente da sociedade, que "nesta, indivíduos formalmente igualizados após a abolição dos privilégios estamentais, perseguiriam livremente os seus próprios interesses privados, ao abrigo das interferências do poder público" (SARMENTO, 2010, p. 41).

Em 1804, fruto, ainda, da Revolução Francesa, surge o código napoleônico, contendo a separação entre Estado e relações privadas bastante assinalada (REIS; BAGATINI, 2012). Conforme os autores explicam sobre esse código:

A codificação do Direito Civil pelo Código Napoleônico trouxe, como todas as demais codificações, a sistematização da matéria objeto de estruturação, arraigada em valores bastante contundentes. A Codificação Civil Francesa trazia, pois, dois valores basilares: o individualismo e o patrimonialismo. Tais valores, tidos como pedras de toque do sistema civil, eram imprescindíveis para que o Estado se mantivesse distante das relações civis (REIS; BAGATINI, 2012, p. 770).

Com a chegada do século XX e a mudança do Estado liberal para o Estado social, passou a ocorrer uma crescente intervenção do Estado em diferentes setores em consequência de pressões sociais e demandas das classes "subalternas" (SARMENTO, 2010, p. 43). Conforme menciona Sarmento (2010), “o poder público, de mero espectador, vai convertendo-se em protagonista das relações econômicas, passando a discipliná-las de forma cogente, através da multiplicação de normas de ordem pública que se impõem diante da autonomia da vontade das partes" (p. 43-44).

No que tange ao cenário jurídico brasileiro, o Código Civil de 1916 teve por base a mesma ideologia contida no código francês, ratificando a ideia da não intervenção do Estado nas relações particulares bem como o viés individualista e patrimonialista (REIS; BAGATINI, 2012). Ao longo de muito tempo, várias Constituições foram editadas, mas o modelo de Direito Civil permaneceu o mesmo, sendo que a Constituição estava voltada à tutela do Direito público e o Código Civil, às relações de Direito privado (REIS; BAGATINI, 2012). Conforme explicam Reis e Bagatini (2012):

Novos conflitos sociais surgiram e, com isso, a imensa necessidade de serem eles regulados. Assim, inicia uma crescente edição de leis esparsas, nominadas como microssistemas jurídicos, alheios ao Código Civil de 1916, que se mostrava desatualizado frente às novas condições da sociedade brasileira. Tantas foram as leis esparsas editadas, que o $\mathrm{CC} / 16$ passou a perder a sua generalidade e completude de 
direito privado, não conseguindo superar sua primazia em relação ao direito civil (p.772).

Diante deste contexto, explicam os autores que “[...] vários doutrinadores passaram a dizer que somente uma norma hierarquicamente superior poderia (re)unificar o direito civil" (REIS; BAGATINI, 2012, p. 772). E, neste ambiente, nasce a Constituição Federal de 1988, incluindo em seu texto normas de direito civil, tornando-se a sua fonte principal, em detrimento do Código (REIS; BAGATINI, 2012, p. 772). Ocorre, assim, uma "[...] releitura das normas e institutos do Direito Privado, filtrados a partir da axiologia constitucional [...]" (SARMENTO, 2010, p.47).

Este fenômeno, explicam Reis e Dias (2011, p. 75) “convencionou-se denominar [...], na órbita civil, de constitucionalização do direito privado, visto que, através de análises hermenêuticas dos fundamentos constitucionais, tornou-se possível dar um novo enfoque a antigos institutos". Conforme explicam os autores, essa nova fase em que o direito se situa, não foi prontamente aceita por todos:

\footnotetext{
Cabe lembrar que houve oposições a esse "tsunami" constitucional, principalmente de doutrinadores civilistas, defensores da autonomia da vontade, compreendendo as novas posturas baseadas nos princípios constitucionais como prejuízo ao desenvolvimento do direito privado, haja vista toda a estruturação alcançada e que se estaria pondo em cheque conceitos como segurança jurídica. No entanto, a discussão acerca dessa inovação foi pouco a pouco sendo dissolvida, pois a sustentação da força normativa da Constituição se mostrou imprescindível para elevar o patamar das relações privadas, de cunho estritamente econômico-social, a um nível mais humano (REIS; DIAS, 2011, p. 75).
}

Embora existam, ainda, outras repercussões da constitucionalização, a maior delas é a expansão dos efeitos da Constituição, pois não há um ramo do direito que se encontre alheio ao texto da Constituição e de sua axiologia. A evolução para o Estado Democrático de Direito, não só esmaeceu a separação entre público e privado, mas também consagrou a dignidade humana como um guia para o Direito, sendo que posturas individualistas e despreocupadas com as questões atinentes à sociedade não encontram mais seu espaço (REIS; DIAS, 2011).

Enfim, no sentido de finalizar este primeiro tópico, Facchini Neto (2010) refere sobre a superação da dicotomia público/privado frente à constitucionalização do direito:

O fenômeno da constitucionalização do direito privado representa, de certa forma, a superação da perspectiva que via o universo jurídico dividido em dois mundos radicalmente diversos: o direito público de um lado e o direito privado de outro. Impõe-se, assim, que se repercorram as razões que originaram tal distinção, sua 
evolução, com a análise dos motivos que levaram à contemporânea relativização de tal diferenciação. (p. 38)

Assim, percebe-se que, contemporaneamente, a visão do Direito compartimentado em duas áreas, estanques e separadas, se encontra desafinada com a percepção mais atual de Direito. Ou seja, atualmente compreende-se que o Direito é um todo do qual fazem parte os ramos público e privado, sendo que ambos encontram sua fonte maior nas normas constitucionais.

Percebe-se, também, que o Direito Civil vem desenvolvendo uma trajetória que se iniciou com um viés individualista e liberal, mas que hoje se encontra superado pelo entendimento de que também deve estar afinado aos preceitos constitucionais - como, por exemplo, o da função social, que impõe seja realizada uma nova leitura de institutos do direito civil como a propriedade.

\title{
3 DIREITOS FUNDAMENTAIS: ANÁlISE CONCEITUAL E DIMENSÕES DOS DIREITOS FUNDAMENTAIS
}

Sobre direitos fundamentais, Sarlet (2010) explica, entre outras lições, que, apesar de ser possível encontrar críticas na literatura, a Constituição brasileira trouxe de maneira expressa uma diferenciação entre os direitos humanos e os direitos fundamentais, sendo aqueles entendidos como posições jurídicas reconhecidas pelo Direito internacional e estes, positivados de maneira expressa ou implícita no âmbito do direito constitucional.

Importa que seja mencionada, ainda, a questão relativa a um duplo caráter dos direitos fundamentais:

\begin{abstract}
Além do mais, verifica-se uma aceitação crescente da noção de que os direitos fundamentais possuem uma dupla dimensão objetiva e subjetiva, da qual é possível extrair uma série de funções e efeitos, como, por exemplo, ocorre com os deveres de proteção estatais [...] e o reconhecimento de uma dimensão organizatória e procedimental [...] dos direitos fundamentais (SARLET, 2010, p. 18).
\end{abstract}

Sarlet explica que os direitos fundamentais, desde o seu reconhecimento, passaram por inúmeras transformações. No contexto das mudanças históricas que ocorreram, convencionou-se falar em pelo menos três gerações de direitos, havendo ainda quem mencione uma quarta. Atenta o autor a respeito de que a palavra gerações poderia levar ao 
errôneo entendimento de que estes direitos seriam substituídos ao longo do tempo (SARLET, 2003).

Embora possam existir notícias na literatura acerca de outras dimensões, o estudo aqui proposto concentra-se apenas nestas quatro dimensões aqui mencionadas. De maneira bastante sucinta, quanto aos direitos fundamentais de primeira dimensão, estes "assumem particular relevo no rol desses direitos, especialmente pela sua notória inspiração jusnaturalista os direitos à vida, à liberdade, à propriedade e à igualdade perante a lei" (SARLET, 2003, p. 51-52). Os direitos de segunda dimensão concedem aos indivíduos o direito a prestações, como assistência social e educação, entre outros, e revelam um mudança entre as liberdades formais para as liberdades materiais (SARLET, 2003).

Quanto aos direitos fundamentais de terceira dimensão, também são chamados de direitos de fraternidade ou solidariedade e são de titularidade coletiva e, por vezes, indefinida, como, por exemplo, o direito ao meio ambiente. Os direitos fundamentais de quarta dimensão, seriam, de acordo com a formulação de Bonavides, aqueles relacionados à democracia, à informação e ao pluralismo (SARLET, 2003). Porém, conforme explica o autor, "[...] a dimensão da globalização dos direitos fundamentais, como formulada pelo Prof. Bonavides, longe está de obter o reconhecimento no direito positivo interno [...] e internacional [...]", tratando-se, para o momento, “[...] de justa e saudável esperança com relação a um futuro melhor para a humanidade [...]" (SARLET, 2003, p. 57).

Os direitos fundamentais são de extrema importância para a constituição de uma sociedade justa, conforme Zaro (2013) menciona:

Os direitos fundamentais possibilitam a organização de um verdadeiro Estado Democrático e Social de Direito. Neles se têm a reserva e constituição da justiça. Os direitos fundamentais são pressupostos, garantias e instrumentos do Estado Democrático de Direito, sempre sob o foco do princípio da dignidade da pessoa humana [...] (p. 37).

\section{APLICAÇÃO DOS DIREITOS FUNDAMENTAIS NO DIREITO PRIVADO: ANÁLISE INICIAL}

No Brasil (e ainda em outros países), a questão sobre vinculação ou não dos Direitos Fundamentais nas relações privadas é objeto de debates, posto que esta previsão não se encontra expressa na Constituição. Em Portugal, por exemplo, há a previsão constitucional da 
vinculação dos Direitos Fundamentais às relações privadas e, mesmo assim, subsiste o questionamento sobre a forma pela qual deve se dar tal incidência (REIS, 2005).

Sobre a teoria da negação da incidência dos Direitos Fundamentais nas relações privadas, menciona-se o caso da Alemanha, onde se negava tal incidência sob, entre outros argumentos, o de que, em ocorrendo tal vinculação, o Direito privado perderia sua identidade e seria submergido pelo Direito constitucional, bem como a autonomia privada deixaria de existir. Esta teoria foi extinta a partir da década de 1950 através de repetidas decisões do Tribunal daquele país, que reconheceram a vinculação existente entre os direitos fundamentais e a seara privada (REIS, 2005).

O entendimento sobre a negação da vinculação, ora em abordagem, persiste em alguns países, como a Suíça e os Estados Unidos, onde os direitos fundamentais, constantes no Bill of Rights, limitam apenas o Estado, com a exceção da $13^{\mathrm{a}}$ emenda que coibiu a escravidão (REIS, 2005).

Sobre a posição estadunidense com relação à negação da incidência dos direitos fundamentais nas relações privadas:

\begin{abstract}
Além do argumento liberal, outra justificativa invocada para a doutrina da state action liga-se ao federalismo. Nos Estados Unidos, compete aos Estados e não à União legislar sobre Direito Privado, a não ser quando a matéria envolva o comércio interestadual ou internacional. Assim, afirma-se que a state action preserva o espaço de autonomia dos Estados, impedindo que as cortes federais, a pretexto de aplicarem a Constituição, intervenham na disciplina das relações privadas (SARMENTO; GOMES, 2011, p. 63-64).
\end{abstract}

Quanto às teorias que entendem pela incidência dos direitos fundamentais nas relações privadas, serão analisadas aqui três destas teorias: a da eficácia imediata, da incidência mediata e dos deveres de proteção.

Em relação à teoria da eficácia imediata ou direta, verificou-se que:

[...] foi defendida inicialmente na Alemanha por Hans Carl Nipperdey, a partir do início da década de 50. Segundo ele, embora alguns direitos fundamentais previstos na Constituição alemã vinculem apenas o Estado, outros, pela sua natureza, podem ser invocados diretamente nas relações privadas, independentemente de qualquer mediação por parte do legislador, revestindo-se de oponibilidade erga omnes (SARMENTO, 2006, p. 220).

A teoria da eficácia mediata ou indireta, por sua vez, “[...] não acarreta sua incidência direta nas relações privadas, mas apenas implica a necessidade de que sejam levados em conta 
pelo Estado na criação legislativa ou na interpretação do direito privado" (PEREIRA, 2006, p. 160).

Por fim, a teoria dos deveres de proteção entende pela imposição ao legislador da tarefa de tutelar os direitos fundamentais, por exemplo, através da criminalização de condutas, e aos juízes o dever de efetivar e promover os direitos fundamentais mediante a atividade hermenêutica (PEREIRA, 2006).

No direito brasileiro, a teoria da eficácia indireta é minoritária, pois a maior parte da doutrina apoia a teoria da eficácia direta, em razão, inclusive, das particularidades da ordem constitucional brasileira (SARMENTO; GOMES, 2011).

Entre os autores mencionados por Sarmento e Gomes (2011) que se vinculam à teoria da eficácia direta, estão, além deles mesmos, Sarlet, Tepedino e Pereira, dentre outros (SARMENTO; GOMES, 2011).

\section{CONCLUSÃO}

As profundas mudanças pelas quais o ordenamento brasileiro passou a partir da promulgação da Constituição Federal de 1988 permitiram que ramos do Direito Privado, historicamente voltado à tutela do indivíduo e de seu patrimônio, passassem ser visto sob nova roupagem, qual seja, a que lhes é dada pelas normas constitucionais.

Assim, os preceitos constitucionais passaram a refletir todas as suas disposições sobre a totalidade do ordenamento jurídico, sendo que o Direito privado não se encontra excluído desta regra. Quanto aos direitos fundamentais, é possível notar a importância destes direitos dentro do cenário jurídico, especialmente em virtude de sua ligação com a preservação do Estado Democrático de Direito.

Por fim, quanto à relação existente entre os direitos fundamentais e as relações privadas, foi possível verificar que esta relação, no âmbito do constitucionalismo contemporâneo, se torna inegável e evidente. A incidência direta dos direitos fundamentais nas relações privadas parece, em virtude das características do sistema jurídico brasileiro, ser a que melhor se adéqua ao cenário nacional contemporâneo. 


\section{REFERÊNCIAS}

FACCHINI NETO, E. Reflexões histórico-evolutivas sobre a constitucionalização do direito privado. In: SARLET, I. W. (Org.). Constituição, direitos fundamentais e direito privado. 3 ed.. Porto Alegre: Livraria do Advogado Editora, 2010.

PEREIRA, J. R. G. Apontamentos sobre a aplicação das normas de direito fundamental nas relações jurídicas entre particulares. In: BARROSO, L. R.(Org.). A nova interpretação constitucional: ponderação, direitos fundamentais e relações privadas. Rio de Janeiro: Renovar, 2006.

REIS, J. R. dos. A vinculação dos particulares aos direitos fundamentais nas relações interprivadas: breves considerações. In: REIS, J. R. dos; LEAL, R. G. (Orgs.). Direitos sociais e políticas públicas: desafios contemporâneos. Santa Cruz do Sul: EDUNISC, 2005. Tomo 5.

REIS, J. R. dos; BAGATINI, J. Novo Sistema Interpretativo do Direito Civil. In: COSTA, M. M. M. da; LEAL, M. C. H.; LEAL, R. G.; REIS, J. R. dos (Orgs.). As Políticas Públicas no Constitucionalismo Contemporâneo. Santa Cruz do Sul: EDUNISC, 2012.

REIS, J. R. dos; DIAS, F. da V. A constitucionalização do direito privado brasileiro: a perspectiva do direito autoral. In: REIS, J. R. dos; BOFF, S. O.; DIAS, F. da V.; PELLEGRINI, G. K. de F.; TOLOTTI, S. M. (Orgs.) Estudos de direito de autor no constitucionalismo contemporâneo. Curitiba: Multideia, 2011.

SARLET, I. W. Neoconstitucionalismo e influência dos direitos fundamentais no direito privado: algumas notas sobre a evolução brasileira. In: SARLET, Ingo Wolfganf (Org.) Constituição, direitos fundamentais e direito privado. 3 ed. Porto Alegre: Livraria do Advogado Editora, 2010.

. A eficácia dos direitos fundamentais. 3 ed. Porto Alegre: Livraria do Advogado, 2003.

SARMENTO, D. Livres e Iguais: Estudos de Direito Constitucional. Rio de Janeiro: Editora Lumen Juris, 2010.

A vinculação dos particulares aos direitos fundamentais no direito comparado e no Brasil. In: BARROSO, L. R. (organizador). A nova interpretação constitucional: ponderação, direitos fundamentais e relações privadas. Rio de Janeiro: Renovar, 2006.

SARMENTO, D.; GOMES, F. R. A eficácia dos direitos fundamentais nas relações entre particulares: o caso das relações de trabalho. Revista TST, Brasília, vol. 77, n. 4, p. 60 - 101, 2011. Disponível em: < http://aplicacao.tst.jus.br/dspace/bitstream/handle/1939/28342/003_sarmento_gomes.pdf?sequ ence $=1>$. Acesso em: 19/02/2014.

ZARO, J. Direitos fundamentais: proporcionando a unidade entre o direito constitucional e o direito privado. In: REIS, J. R. dos; CERQUEIRA, K. L. (Orgs.). Intersecções jurídicas entre o publico e o privado. Santa Cruz do Sul: IPR, 2013. 